Çukurova Üniversitesi Mühendislik Mimarlık Fakültesi Dergisi, 33(4), ss. 57-66, Aralık 2018

Çukurova University Journal of the Faculty of Engineering and Architecture, 33(4), pp. 57-66, December 2018

\title{
Doğaltaş Ocaklarında Martopikör Kullanımında El-Kol Titreşim Maruziyetinin İncelenmesi
}

\author{
Ali Ekrem ARITAN*1, Melek TÜMER ${ }^{1}$ \\ ${ }^{1}$ Afyon Kocatepe Üniversitesi, Mühendislik Fakültesi, Maden Mühendisliği Bölümü, \\ Afyonkarahisar
}

Geliş tarihi: 09.08.2018 Kabul tarihi: 25.12 .2018

$\ddot{\mathbf{O z}}$

$\mathrm{Bu}$ çalışmada, doğaltaş madenciliğinde kullanılan martopikörün çalışanlar üzerindeki kişisel titreşim maruziyet boyutu incelenmiştir. Bu incelemeler sedimanter, metamorfik ve magmatik kökenli toplam 25 doğaltaş maden ocağında yapılmıştır. Ölçümler, çalışanlardan titreşim sönümleyici eldivenli ve eldivensiz alınmıştır. TS EN ISO 5349-1 [1] standardı esas alınarak yapılan ölçümler RMS (m/ $\mathrm{s}^{2}$ ) olarak hesaplanmıştır. Bulunan değerler, maruziyet puanlama sistemine göre değerlendirilmiştir. Değerlendirme sonucunda, eldivensiz çalışmada; 5451 ile 15798 puan arasında değişirken, titreşim sönümleyici eldiven kullanıldığında 3666 ile 11725 puan arasında değiştiği görülmüştür. Bu sonuçlar; martopikör kullanan çalışanların el kol titreşimi (EKT) maruziyeti sonucunda ciddi bir sağlık ve güvenlik sorunu olabileceğini göstermiştir. İşverenler, maruziyeti azaltmak için "Çalışanların Titreşimle İlgili Risklerden Korunmalarına Dair Yönetmelik” kapsamında aktif adımlar atmaları gerekmektedir.

Anahtar Kelimeler: Doğaltaş madenciliği, Titreşim, Mesleki maruziyet, TS EN ISO 5349-1

\section{Investigation of Hand-Arm Vibration Exposure in the Use of Pneumatic Hammer in the Natural Stone Quarries}

\begin{abstract}
In this study, the personal vibration exposure dimension of the pneumatic hammer used in natural stone mining was investigated. These investigations were carried out in a total of 25 natural stone mines of sedimentary, metamorphic and magmatic origin. Measurements were taken from employees with vibrating gloves and without gloves. Measurements based on TS EN ISO 5349-1 [1] standard were calculated as RMS $\left(\mathrm{m} / \mathrm{s}^{2}\right)$. The values were evaluated according to the exposure point system. As a result of the evaluation, the non-glove study ranged between 5451 and 15798 points, while the vibration damper glove ranged between 3666 and 11725 points. These results have shown that employees using pneumatic hammer may have a serious health and safety problem as a result of HAV (hand-arm vibration) exposure. Employers must take active steps in accordance with the regulation to reduce exposure.
\end{abstract}

Keywords: Natural stone mining, Vibration, Occupational exposure, TS EN ISO 5349-1

*Sorumlu yazar (Corresponding author): Ali Ekrem ARITAN, aritan@aku.edu.tr 


\section{GíRiș}

Türkiye, doğaltaş sektöründe dünya ülkelerine ihracat yapan bir ülkedir. Ülkemizin doğaltaş pazar payı \% 34,71'dir. Ülkemizde doğaltaş üretimi yıllık 11,5 milyon ton olup doğaltaş işleme tesislerinin plaka üretim kapasitesi toplam 6,5 milyon $\mathrm{m}^{2}$ civarındadır [2].

İş sağlığı ve güvenliği açısından bakıldığında, Ülkemiz ekonomisi için önemli yere sahip olan doğaltaş madenciliğine gerekli önemin verilmediği ve istatistikler incelendiğinde, rapor edilmiş çalışanların fiziksel risk etmenleri ile ilgili meslek hastalığı olmadığ1 görülmektedir [2].

Doğaltaş madenciliğinde çalışanlar işyerinde aktiviteleri esnasında, ayakta dururken, otururken çalışırken vb. hallerde titreşim kaynağı ile temas halinde iken titreşime maruz kalırlar. Titreşim sebepli sağlık etkileri yani meslek hastalıkları, genellikle birkaç yıl süren titreşim maruziyetinden sonra ortaya çıkar [3].

Birçok endüstride ve meslekte çalışanlar için el-kol titreşimi (EKT), yaygın bir tehlikedir. İşyerinde EKT maruziyeti, el tipi elektrikli aletlerin (darbeli matkaplar), el kılavuzlu makinelerin (martopikör) ve el ile beslenen makinelerin (ögüutücüler) kullanımından kaynaklanabilir. $\mathrm{Bu}$ titreşime düzenli ve uzun süreli maruziyet, operatörün sağlığını etkileyebilir.

Ancak titreşimden kaynaklanan riskler kontrol edilebilir ve çalışanlar, titreşimin neden olduğu kötü etkilere karşı korunabilir. Çalışanları korumak ve titreşim düzenlemelerine uymak için işverenler, riskleri değerlendirmeli ve bunları nasıl kontrol edeceklerini planlamalıdır [4].

$\mathrm{Bu}$ çalışmada, farklı doğaltaş ocaklarında çalışanların martopikör kullanımı sonucu el-kol titreşimine mesleki maruziyetlerinin boyutu incelenmiştir. Ayrıca kişisel koruyucu donanımın gerekliliğini ortaya koymak amacıyla, kişisel koruyucu donanımla ölçümler alınarak titreşim sönümleme miktarları ve sönümleme oranları belirlenmiştir. EKT büyüklükleri göz önünde bulundurularak risk değerlendirme yapılmış ve sağlık etkileri konusunda bilgi verilmiştir.

\section{TITREŞIM}

Titreşim, frekansı, büyüklüğü ve süresi ile karakterize edilen, bir referans noktası etrafındaki salınımlı harekettir [5]. Periyodik titreşim, bir parçacık veya gövdenin, bir referans pozisyonu etrafında salınan hareketi olarak görülebilir, hareket belirli zaman aralıklarından sonra kendini tekrar eder. Periyodik titreşimin en basit şekli, zamanın bir fonksiyonu olarak çizildiğinde, sinüzoidal bir eğri ile temsil edilen, harmonik harekettir [6] (Şekil 1).

Titreşimin büyüklüğü $(\mathrm{m})$, hızı $(\mathrm{m} / \mathrm{s})$ veya ivmesi $\left(\mathrm{m} / \mathrm{s}^{2}\right)$ ile ölçülebilir. RMS (root mean square, karekök ortalama) büyüklüğü, titreşim enerjisi ve dolayısıyla titreşim hasar potansiyeli ile ilgilidir. $-x$, -y ve $-z$ eksenleri için RMS (titreşim toplam değeri olarak da bilinir), ivme frekansının karekök toplamidır [7].

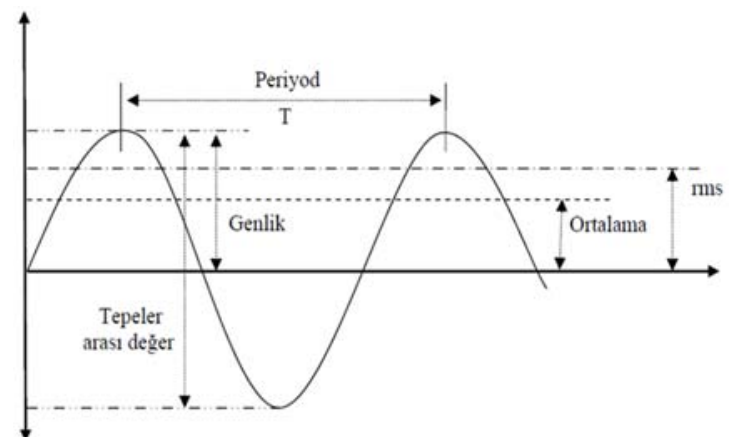

Şekil 1. Titreşim dalgası [8]

2002/44/EC sayılı “AB Direktifi ve Çalışanların Titreşimle İlgili Risklerden Korunmalarına Dair Yönetmelik", hem elle iletilen titreşim hem de tüm vücut titreşimi için "günlük maruz kalma eylemi değerlerini" ve "günlük maruz kalma sınır değerlerini” belirtmektedir (Çizelge 1). Direktif ve yönetmelikte açıklandığı üzere idari, teknik ve tıbbi önlemlerin işverenler tarafından uygulanması gerekmektedir. Çalışanların titreşime maruz kalmasından kaynaklanan risklere karşı korumayı amaçlamaktadır [9-10]. 
Çizelge 1. Titreșim maruziyet değerleri

\begin{tabular}{|l|c|l|}
\hline & $\begin{array}{c}\text { El-Kol } \\
\text { Titreşimi } \\
\mathrm{A}(8)\end{array}$ & \multicolumn{1}{|c|}{ Tanımlar } \\
\hline $\begin{array}{l}\text { Maruziyet } \\
\begin{array}{l}\text { Eylem } \\
\text { Değeri }\end{array}\end{array}$ & $2,5 \mathrm{~m} / \mathrm{s}^{2}$ & $\begin{array}{l}\text { Bir veya daha fazla } \\
\text { önlemin* alındığı değer. }\end{array}$ \\
\hline & & $\begin{array}{l}\text { Korunmasız bir çalışanın } \\
\text { kabul edilemez risklere } \\
\text { maruz kaldığı değer. Bu } \\
\text { değerin aşılmas yasaktır } \\
\text { ve yaruziyet } \\
\text { Sinır } \\
\begin{array}{l}\text { Değeri } \\
\text { uygulanarak yönetmelik** } \\
\text { alınmalıdır. }\end{array}\end{array}$ \\
* Bilgilendirme, eğitim, teknik önlemler, sağlık denetimleri. \\
** Sağlık ve güvenliğin korunması için uygun önlemler.
\end{tabular}

\subsection{El-Kol Titreșimi (EKT)}

El-kol titreşimi; insan el-kol sistemine iletildiğinde, çalışanların sağlık ve güvenliği için risk oluşturur. Özellikle vasküler, kemik veya eklem ile nörolojik veya kas bozuklukları meydana getirir [11]. İnsanın titreşime ve darbelere verdiği tepkiyi dikkate alarak, hem mekanik hem de psikolojik etkilerini dikkate almak gerekir [8].

İnsan vücudu hem fiziksel hem de biyolojik olarak son derece karmaşık bir yapıya sahip bir sistemdir. EKT maruziyeti sırasında oluşan rahatsızlıklar ile ilgili değişkenler; vibrasyonun karakteristikleri, araçlar veya işlemler, maruziyet koşulları, toplam maruziyet süresi ve kişisel karakteristiklerdir. Vibrasyonun karakteristikleri; büyüklük, frekans ve yön (-x, $-\mathrm{y}$ ve $-\mathrm{z}$ eksenleri) olarak tanımlanırken araçlar veya işlemler araç tasarımı ve araç tipidir (Vurgulu, dönen, dönerek vurgulu) [12].

$\mathrm{Xu}$ ve arkadaşlarının [13] Kuzey Çin kömür madeninde EKT'ye sebep olan aletler kullanarak kömür çalışanlarıyla ilgili belirtileri tespit etmek ve EKTS için risk faktörlerini belirlemek için çalışma yapmışlardır. Titreşime maruziyet süreleri farklı olmakla birlikte el uyuşma sıklı̆ı̆, karpal tünel sendromu, el ağrısı, kulak çınlaması, hafiza kaybı, baş dönmesi ve baş ağrısı gibi rahatsızlıkları raporlamışlardır.

Elle iletilen titreşimin yönü Şekil 2'de görüldüğü gibi yapılan işin durumuna göre iki şekilde tespit edilmektedir.

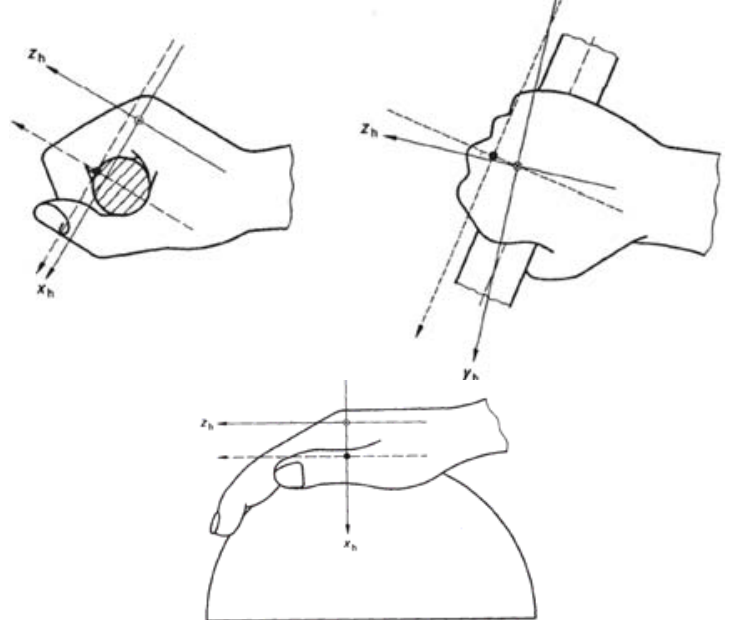

Şekil 2. El kavrama ve avuç içi konumu [13]

Kişisel el-kol titreşim maruziyetini ölçmek için toplam değer hesaplaması Eşitlik 1'e göre yapılmaktadır [11]. RMS ivmeleri $\left(a_{\mathrm{wx}}, \mathrm{a}_{\mathrm{wy}}, \mathrm{a}_{\mathrm{wz}}\right)$, TS EN ISO 5349-1'de [1] tarif edilen uygun ağırlıklandırma faktörleri kullanılarak hesaplanmaktadır $\left(\mathrm{x}\right.$-ekseni $=\mathrm{h}_{\mathrm{wx}} ; \mathrm{y}$ - ekseni $=\mathrm{h}_{\mathrm{wy}}$; $\mathrm{z}$ - ekseni $=\mathrm{h}_{\mathrm{wz}}$ ).

$a_{h v}=\sqrt{a_{h w x}^{2}+a_{h w y}^{2}+a_{h w z}^{2}}$

Günlük titreşime maruz kalma $\mathrm{A}$ (8), işverenlerin sağladığı maruz kalma süresinin "bildirilen frekans ağırlıklı RMS hızlanma titreşim toplam değerinin" beyan edilen değerlerinden hesaplanır. Günlük maruz kalma süresi, çalışma günündeki titreşime maruz kalan el(ler) in toplam zamanıdır. Titreşime maruz kalma süresi, kişinin güç araçları veya işyerlerinde çalışma süresi daha kısa olabilir. Çeşitli çalışma koşulları ve süreleri ve zamanlamaları için uygun temsilci numuneleri için günlük toplam maruziyet süresini tahmin etmek önemlidir. Günlük titreşime maruz kalma A (8) (8 saatlik bir enerji eşdeğeri frekans ağırlıklı RMS hızlanma değeri), Eşitlik 2 tarafından, frekans ağırlıklı RMS hızlanma toplam değeri kullanılarak bulunur. Bu nedenle, farklı günlük titreşim maruz kalma süreleri ile kolay karşılaştırmalar yapılabilir. Bir çalışanın günlük kişisel titreşim maruziyeti (A (8)) saniyede metre kare cinsinden ifade edilir $\left(\mathrm{m} / \mathrm{s}^{2}\right)$ ve formülü kullanarak tanımlanmıştır [11]: 


$$
A(8)=a_{h v} \sqrt{\frac{T}{T_{0}}}
$$

Burada; T: Titreşim büyüklüğüne maruz kalma süresidir. $\mathrm{T}_{0}: 8$ saat referans süresidir.

Eğer çalışma, günlük toplam titreşim maruziyetinin, farklı titreşim büyüklüklerine sahip birkaç işlemden oluşuyorsa, o zaman günlük titreşim maruziyeti, A(8), Eşitlik 3 kullanılarak elde edilecektir:

$$
A(8)=\sqrt{\frac{1}{T_{0}} \sum_{i=1}^{n} a_{h v i}^{2} T_{i}}
$$

Burada; $a_{\text {hvi: }}$ i işleminin titreşim toplam değeridir. $\mathrm{n}$ : bireysel titreşim maruziyetinin sayısıdır. $\mathrm{T}_{\mathrm{i}}$ : $\mathrm{i}$ işleminin süresidir [1].

Maruziyet koşulları süre ve maruziyet şekline (sürekli, kesikli, dinlenme periyotları) bağlı değişkendir. Toplam maruziyet süresi; çevresel şartlar, ortam sıcaklığı, hava akım hızı, nemlilik, gürültü, parmak el- kol sisteminin dinamik cevabı ve vibrasyonun iletilebilirliği, absorbe edilen enerji ile ilişkilidir. Çalışma metodu (kavrama kuvveti, itme kuvveti, el-kol postürü, vücut pozisyonu), sağlık, eğitim, beceriler, eldiven kullanımı ve hasara karşı kişisel hassasiyet ise kişisel karakteristik değişkenleridir [12].

El-kol titreşimi, el ve kollara avuç içi ve parmaklardan iletilen titreşimden kaynaklanır. Makinenin tutamağı ya da bir alet parçasının yüzeyi hıla titreşir ve bu hareket elinize ve kolunuza ekipman tutulduğu esnada iletilir [14]. El-kol sistemi aracılığıyla titreşim aktarılabilirliği, elin fiziksel özelliklerine, el tutacağına, takım çalıştırma tekniğine ve aletle temas halindeki el alanına, itme kuvvetine bağlı olarak elin biyodinamik cevabı ile büyük ölçüde belirlenir [5].

\subsection{Maruziyet Puanlama Sistemi ve Hazır Hesap}

Günlük titreşim maruziyetini belirleyen basit bir yöntem, Şekil 3 ve 4'de tasvir edilen nokta temelli bir sistemin kullanılmasıdır. $\mathrm{Bu}$ yöntemin kullanımı; maruziyet süresine karşılık gelen, maruziyet büyüklüğü ile kesişen puanın okunması yoluyla olmaktadır. Maruz kalma eylem ve sınır değerlerine karşılık gelen maruz kalma puanları [11]:

- Maruziyet eylem değeri EKT için 100 puan.

- Maruziyet sınır değeri EKT için 400 puan.

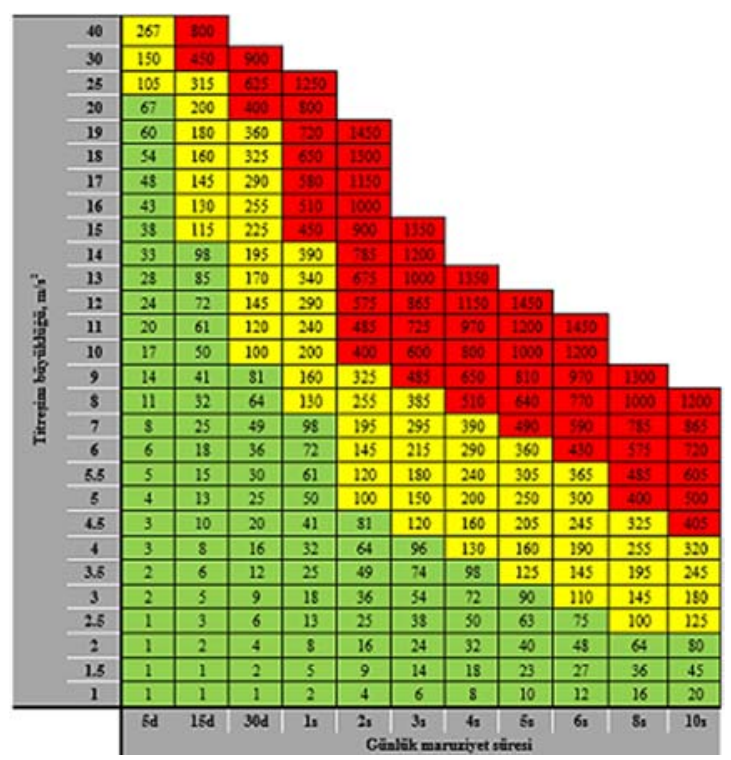

Şekil 3. Maruziyet puanları

HSE, EKT hesap makinesi, HSE web sitesinin sayfalarından indirilebilen bir elektronik tablodur (Şekil 3). Hesap makinesi, günlük titreşim maruziyeti tahminlerini hesaplamak için tasarlanmıştır. Kullanıcının ayarlama yapmasını, iş modellerinde ve makinelerde meydana gelen değişikliklerin maruziyeti nasıl etkileyebileceğini göstermektedir.

Şekil 3'de puanlamalar renklerle sınırlandırılmıştır. Bu renkler; kırmızı: maruziyet sınır değerinin üstünde olunduğunu, sarı: maruziyet eylem değerinin üstünde olunduğunu, yeşil ise maruziyet eylem değerinin altında olunduğunu göstermektedir. 


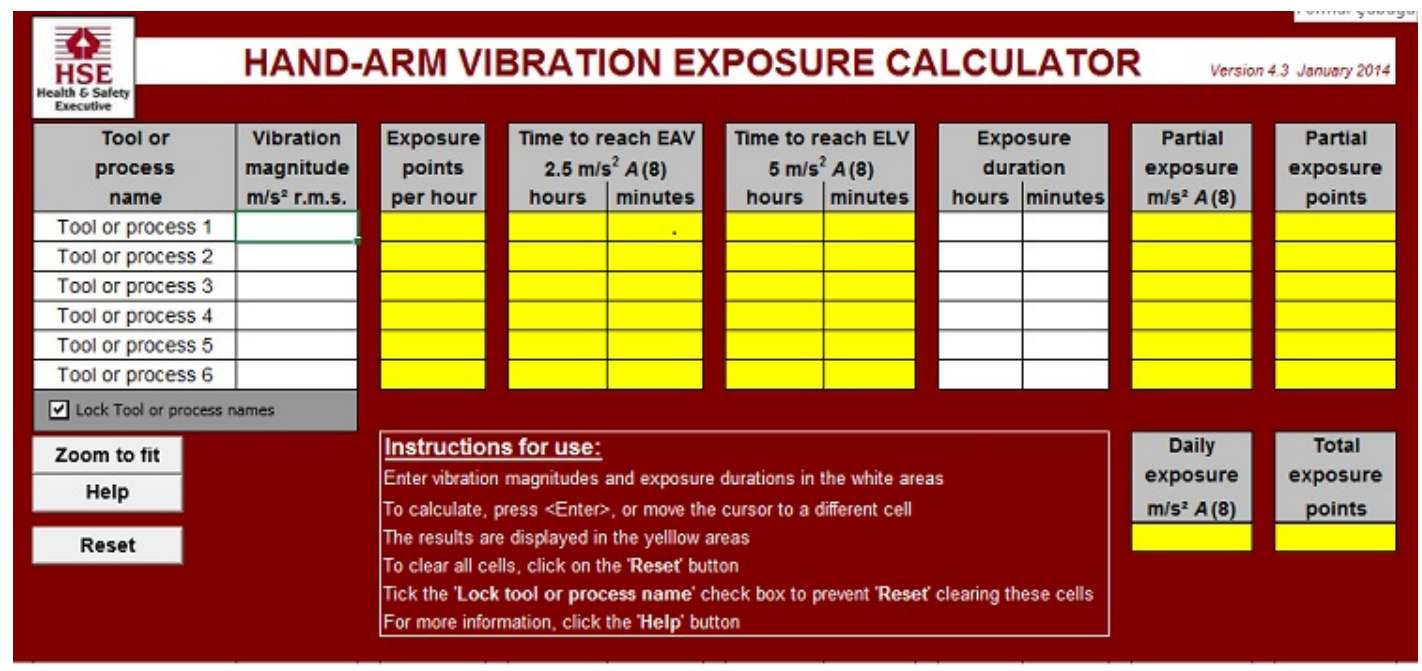

Şekil 4. Maruziyet puanları

\section{MATERYAL VE METOT}

Çalışma, Afyonkarahisar ve Ankara İl sınırları içerinde bulunan 25 doğaltaş ocağında yapılmıştır. $\mathrm{Bu}$ ocaklarda on tanesi sedimanter, sonraki 10 tanesi metamorfik, son 5 tanesi magmatik kökenli doğaltaş ocağıdır.

Ocaklarda bulunan martopikörlerde titreşim maruziyet ölçümleri yapılmaya başlanmadan önce, normal çalışma şartlarına ulaşmak amacıyla makinanın 1sınması için yeterli zaman (TS EN 1032+A1, 2011 standardına göre en azından 10 dakika) ve makinanın belirli bir aralıkta çalışması sağlanmıştır [15].

El-kol titreşimi ölçümleri alınırken, titreşimin vücuda girdiği yere en yakın nokta olan bilekten ölçümler alınmıştır. Ölçümlere başlanmadan ocakta ölçüm alınacak martopikörlerin çalışma süresini ve bakım periyodunu kontrol amaçlı ön inceleme yapılmıştır. Titreşime sebep olan tüm çalışma koşulları incelenerek titreşime maruz kalma değerini yüksek oranda etkilemesi muhtemel olan işler belirlenmiştir. Ölçüm alınacak süre 7 dakikadan az olmayacak şekilde $-\mathrm{x},-\mathrm{y}$ ve $-\mathrm{z}$ eksenleri ile ölçüm alınmıştır. Titreşim genliğini belirlemek için $\mathrm{m} / \mathrm{s}^{2}$ biriminden frekans ağırlıklı ivmenin RMS değerinden ölçümler alınmıştır. Günlük titreşime maruziyet ölçümleri için 8 saatlik frekans ağırlıklı toplam titreşim değeri $\mathrm{A}(8)$ ile ifade edilir.

Ocak içerisinde el-kol titreşim maruziyetini belirlemek için CESVA VC 431 cihazı el-kol uygulamaları için AC031 üç eksenli ivmeölçer ile el-kol titreşim probu kullanılarak, titreşimin vücuda girdiği en yakın nokta olan bilekten ölçümler alınmıştır (Şekil 5). Titreşimin ölçülmesi için Uluslararası Standartlar Örgütü (ISO), standart ölçü birimi olarak RMS'i önermiştir. $\mathrm{Bu}$ doğrultuda, TS EN ISO 5349-1 [1] standardı esas alınarak yapılan ölçümlerde titreşim $\mathrm{RMS}\left(\mathrm{m} / \mathrm{s}^{2}\right)$ olarak hesaplanmıştır.

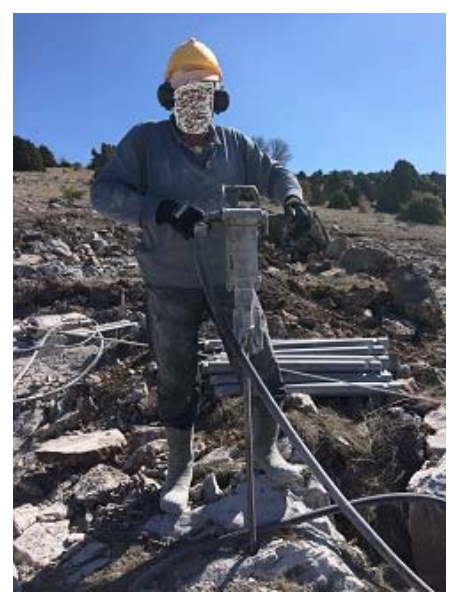

Şekil 5. El-kol titreşim ölçümü 


\section{BULGULAR}

Doğaltaş ocaklarında mevcut durumda çalışan, bakımları yapılmış ekipmanların operatörlerinden alınan el-kol titreşim maruziyet değerleri Çizelge 5'de verilmiştir. Çalışma kapsamında EKT maruziyeti önlemek amaciyla, titreşim sönümleyici eldiven ile alınan ölçümler Çizelge 3'de verilmektedir.

Ocaklardan alınan EKT ölçüm sonuçları "Çalışanların Titreşimle İlgili Risklerden Korunmalarına Dair Yönetmelik" kapsamında değerlendirildiğinde; martopikör kullanan çalışanlarda alınan EKT ölçüm sonuçlarına bakıldığında maruziyet sınır değerinin çok üstünde olduğu tespit edilmiştir [10].

Çizelge 2. El-kol titreşim maruziyeti, $\mathrm{A}(8)\left(\mathrm{m} / \mathrm{s}^{2}\right)$

\begin{tabular}{|c|c|c|c|c|}
\hline \multicolumn{2}{|c|}{ Ocak } & \multirow{2}{*}{$\begin{array}{c}\begin{array}{c}\text { Eldivensiz } \\
\left(\mathbf{m} / \mathbf{s}^{\mathbf{2}}\right)\end{array} \\
19,31\end{array}$} & \multirow{2}{*}{$\begin{array}{c}\begin{array}{c}\text { Eldivenli } \\
\left(\mathbf{m} / \mathbf{s}^{\mathbf{2}}\right)\end{array} \\
16,75 \\
\end{array}$} & \multirow{2}{*}{$\begin{array}{c}\Delta \text { Fark } \\
(\mathbf{( \% )}) \\
13,26 \\
\end{array}$} \\
\hline \multirow{10}{*}{ 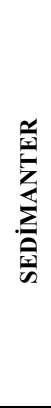 } & $\mathrm{O} 1$ & & & \\
\hline & $\mathrm{O} 2$ & 18,55 & 15,20 & 18,06 \\
\hline & $\mathrm{O} 3$ & 20,01 & 17,70 & 11,54 \\
\hline & $\mathrm{O} 4$ & 19,77 & 17,34 & 12,29 \\
\hline & $\mathrm{O} 5$ & 19,13 & 15,13 & 20,91 \\
\hline & O6 & 18,87 & 16,47 & 12,72 \\
\hline & $\mathrm{O} 7$ & 19,94 & 17,55 & 11,99 \\
\hline & O8 & 19,09 & 16,51 & 13,51 \\
\hline & O9 & 20,16 & 17,73 & 12,05 \\
\hline & $\mathrm{O} 10$ & 18,45 & 16,11 & 12,68 \\
\hline \multirow{10}{*}{ 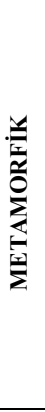 } & O11 & 20,78 & 19,44 & 6,45 \\
\hline & $\mathrm{O} 12$ & 20,81 & 17,46 & 16,10 \\
\hline & O13 & 23,45 & 21,54 & 8,14 \\
\hline & O14 & 20,34 & 18,81 & 7,52 \\
\hline & O15 & 21,96 & 19,94 & 9,20 \\
\hline & O16 & 22,14 & 20,04 & 9,49 \\
\hline & O17 & 23,13 & 20,07 & 13,23 \\
\hline & O18 & 21,33 & 19,23 & 9,85 \\
\hline & O19 & 21,42 & 19,47 & 9,10 \\
\hline & $\mathrm{O} 20$ & 20,37 & 18,69 & 8,25 \\
\hline \multirow{5}{*}{ 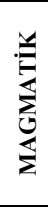 } & $\mathrm{O} 21$ & 29,61 & 25,78 & 12,93 \\
\hline & $\mathrm{O} 22$ & 31,41 & 26,07 & 17,00 \\
\hline & $\mathrm{O} 23$ & 30,24 & 27,06 & 10,52 \\
\hline & O24 & 28,17 & 26,01 & 7,67 \\
\hline & $\mathrm{O} 25$ & 29,16 & 25,31 & 13,20 \\
\hline
\end{tabular}

\section{TARTIŞMA}

Martopikörlerde yay ve sönümleme elemanları bulunmadığından çalışanlar yüksek EKT'ye maruz kalmaktadırlar. Yönetmelikte belirtilen maruziyet sınır değeri $5 \mathrm{~m} / \mathrm{s}^{2}$ iken martopikör kullanan çalışanlardan ölçülen en düşük EKT maruziyet miktarı, eldivensiz $18,45 \mathrm{~m} / \mathrm{s}^{2}$, eldivenli $15,13 \mathrm{~m} / \mathrm{s}^{2}$ olarak ölçülmüştür [10]. Bu durum çalışanların sağlığının ciddi şekilde tehlike altında olduğunu göstermektedir [13]. Magmatik kökenli doğaltaş ocaklarında (21-25 no'lu ocaklar) alınan titreşim ölçümleri Şekil 6'da görüldügüu üzere daha yüksek çıkmıştır.

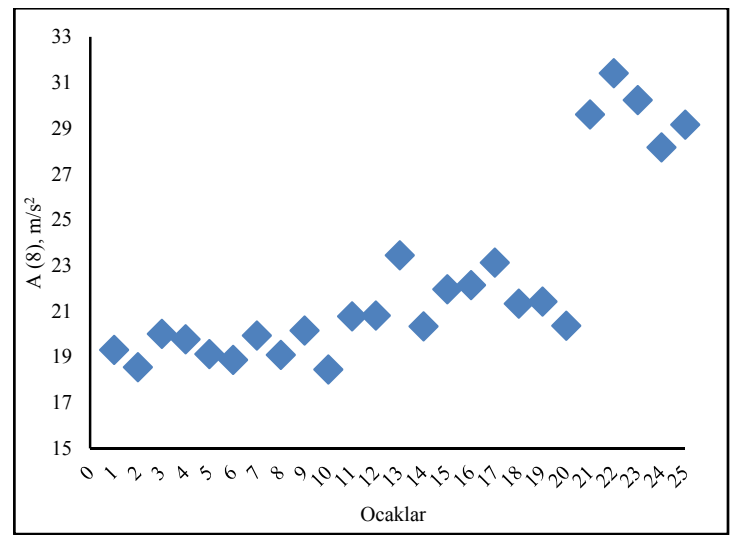

Şekil 6. Eldivensiz A (8) ölçümleri

Martopikör kullanan çalışanlarda eldivenli alınan EKT ölçüm sonuçları, titreşim büyüklüğünün azaldığını fakat sınır değerine $\left(5 \mathrm{~m} / \mathrm{s}^{2}\right)$ indirilemediğini göstermektedir (Şekil 7).

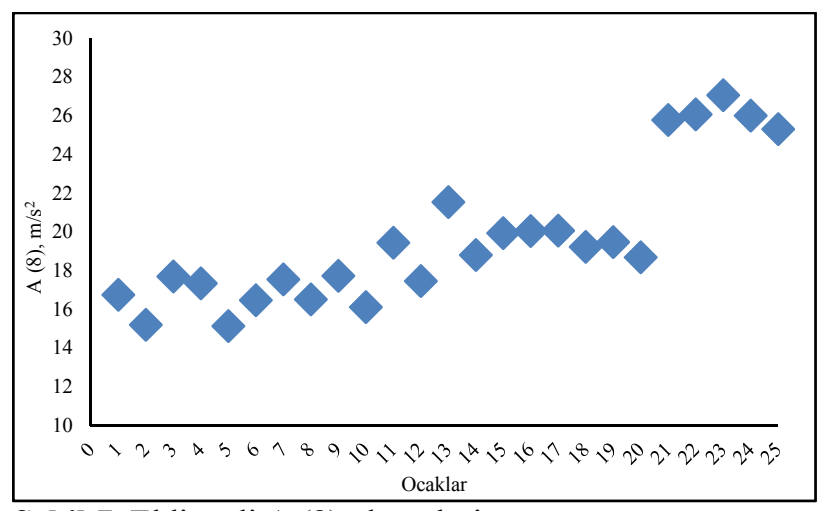

Şekil 7. Eldivenli A (8) ölçümleri 
Eldivensiz alınan titreşim ölçümlerin sonucu; sedimanter kökenli doğaltaşlarda ortalama $19,33 \mathrm{~m} / \mathrm{s}^{2}$ iken metamorfik kökenli doğaltaşlarda $21,57 \mathrm{~m} / \mathrm{s}^{2}$ ve magmatik kökenli doğaltaşlarda alınan ölçümlerin ortalamasının ise $29,72 \mathrm{~m} / \mathrm{s}^{2}$ olduğu görülmüştür.

Eldivenli alınan titreşim ölçümlerin sonucu; sedimanter kökenli doğaltaşlarda ortalama $15,24 \mathrm{~m} / \mathrm{s}^{2}$ iken metamorfik kökenli doğaltaşlarda $17,79 \mathrm{~m} / \mathrm{s}^{2}$ ve magmatik kökenli doğaltaşlarda alınan ölçümlerin ortalamasının ise $21,49 \mathrm{~m} / \mathrm{s}^{2}$ olduğu görülmüş̧tür.

Çizelge 3. Maruziyet puanlama sistemine göre EKT değerlendirme

\begin{tabular}{|c|c|c|}
\hline \multirow[t]{2}{*}{ Çalışan } & \multicolumn{2}{|c|}{ Toplam Maruziyet Puanı } \\
\hline & Eldivensiz & Eldivenli \\
\hline 1 & 5971 & 4493 \\
\hline 2 & 5510 & 3700 \\
\hline 3 & 6412 & 5017 \\
\hline 4 & 6259 & 4815 \\
\hline 5 & 5860 & 3666 \\
\hline 6 & 5702 & 4344 \\
\hline 7 & 6367 & 4932 \\
\hline 8 & 5836 & 4365 \\
\hline 9 & 6508 & 5034 \\
\hline 10 & 5451 & 4156 \\
\hline 11 & 6915 & 6052 \\
\hline 12 & 6935 & 4882 \\
\hline 13 & 8806 & 7430 \\
\hline 14 & 6625 & 5666 \\
\hline 15 & 7722 & 6367 \\
\hline 16 & 7849 & 6431 \\
\hline 17 & 8567 & 6450 \\
\hline 18 & 7285 & 5921 \\
\hline 19 & 7347 & 6070 \\
\hline 20 & 6644 & 5594 \\
\hline 21 & 14039 & 10642 \\
\hline 22 & 15798 & 10883 \\
\hline 23 & 14643 & 11725 \\
\hline 24 & 12707 & 10833 \\
\hline 25 & 13616 & 10258 \\
\hline
\end{tabular}

Ölçüm sonuçları maruziyet puanlama sistemine göre değerlendirilmiştir (Çizelge 3). $\mathrm{Bu}$ değerlendirme Şekil 3'deki maruziyet planlaması çizelgesinde rakamlara karşılık gelen renklere göre yapılmıştır. 25 ocaktan alınan ölçüm sonuçlarının değerlendirmesinin tamamı kırmızı bölgede yer almıştır. Sisteme göre maruziyet sınır değeri EKT için 400 puandan başlamaktadır [4].

Hesaplamalarda ise en düşük (eldivenli) 3666 çıkmıştır. Bu değer sınır değerin 9 katından fazladır. Bu sonuç riskin ne kadar büyük olduğunu görmemize yetmektedir.

Martopikör kullanan eldivensiz çalışanlardan alınan titreşim maruziyeti ölçüm sonuçları, HSE hazır hesap tablosunda çalışma zamanına bakıldığında yeşil bölgede olacak şekilde ortalama 6 dakika, eldivenli çalışmada ise 9 dakikanın üzerinde çalışılmaması gerektiği hesaplanmıştır. Bir çalışan 8 saatlik vardiyada eldivenli 9, eldivensiz 6 dakikanın üzerinde çalışması halinde maruziyet eylem değerine ulaşacaktır. Maruziyetin sarı bölgede yer alması için ortalama, eldivensiz 24 dakika, eldivenli 34 dakikanın üzerinde çalışılmaması gerekmektedir.

\section{SONUÇLAR VE ÖNERİLER}

Martopikörün mekanik titreşimi, kayacın kökeni, zemin pürüzlülüğü yanı sıra ekipmanın bakımını da içeren çok faktörlü bir risk faktörüdür. $\mathrm{Bu}$ nedenle, belirli bir çalışma koşulunda güvenli olarak sınıflandırılan bir martopikör, başka bir çalışma ortamında insan sağlığı için bir risk oluşturabilir.

Madencilik karakteristik olarak sürekli değişen bir süreçtir, titreşim maruziyeti için periyodik olarak kişisel maruziyet ölçümleri alınmalıdır.

Mühendislik kontrolünün uygulanmas1, martopikörlerin bakımı ve kişisel koruyucu donanımların kullanımı, titreşim nedeniyle sağlık riskinin azaltılmasına katkıda bulunabilir. Kurumsallaşmış bir işletmede iyi bir titreşim maruziyeti izleme sistemi geliştirilmelidir.

Burada sunulan bulgular, sedimanter kökenli doğaltaşlarda titreşim eldiveninin kullanımı ile ortalama \%13,90, metamorfik kökenli doğaltaşlarda \%9,73 iken magmatik kökenli 
doğaltaşlarda \%12,26 titreşim maruziyeti düşüşünün olduğunu göstermiştir (Şekil 8).

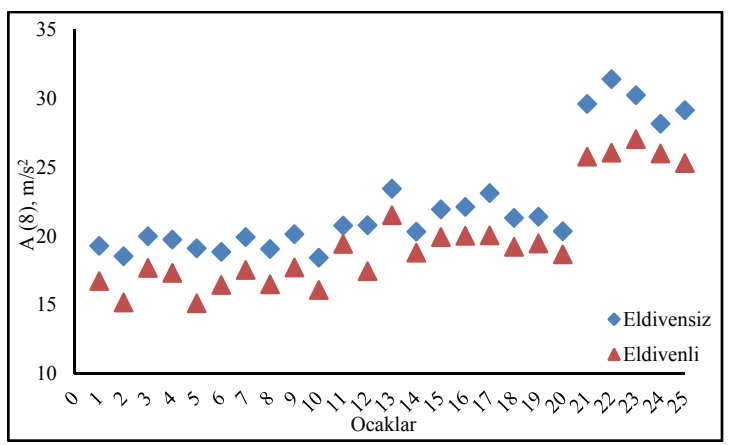

Şekil 8. $\quad$ Eldivensiz/eldivenli $\mathrm{A}(8) \quad$ ölçümleri karşılaştırması

Ölçülen titreşim büyüklükleri göz önünde bulundurulduğunda martopikör kullanan çalışanların yüksek derecede EKT'ye maruz kaldıkları görülmektedir (Çizelge 3). Titreşim sönümleyici eldivenler ile alınan ölçümlerden görüldüğü üzere; eldivenler titreşimi bir miktar sönümleyerek maruziyet miktarını azaltmaktadır. Çizelge 2'de görüldüğü üzere, kişisel koruyucu donanım olarak kullanılan titreşim sönümleyici eldiven, çalışanları titreşim maruziyetinden tam manasıyla korumadığı ancak azalttığı görülmektedir.

HSE hazır hesap tablosunda yapılan yeşil ve sarı bölge çalışma zamanı hesaplamaları bize çalışma zamanlarının elde ettiğimiz dakikalara düşürülmesinin imkânsız olduğunu göstermiştir. $\mathrm{Bu}$ da; martopikör tasarımının değiştirilmesi, teknik gelişmelere uyum sağlanması, sehpalı yani direk çalışanın doğrudan temas etmediği düzeneklerin kurulması vb. alınabilecek farklı önlemlerin araştırılması gerektiğini göstermektedir [16].

\section{KAYNAKLAR}

1. TS EN ISO 5349-1, 2005. Türk Standartları, Mekanik Titreşim-Kişilerin Maruz Kaldığı, Elle İletilen Titreşimin Ölçülmesi ve Değerlendirilmesi-Bölüm 1: Genel Kurallar, TSE, Ankara.
2. Türkiye Cumhuriyeti Ekonomi Bakanlığı, 2018. Doğaltaş Sektörü, Sektör Raporları.

3. Fritz, M., 2000. Description of the Relationship Between the Forces Acting in the Lumbar Spine and Whole Body Vibrations By Means of Transfer Functions, Clin Biomech (Bristol Avon), 15, 234-40.

4. Health and Safety (HSE)., 2005. Hand-Arm Vibration and Whole Body Vibration, www.hse.gov.uk/vibration, 12.03.2018.

5. Griffin, M.J., 1990. Handbook of Human Vibration, Academic Press, London.

6. South, T., 2004. Managing Noise and Vibration at Work, 1. Edition, London.

7. Eger, T., Contratto, M., Dickey, J.P., 2011. Influence of Driving Speed, Terrain, Seat Performance and Ride Control on Predicted Health Risk Based on ISO 2631-1 and EU Directive 2002/44/EC, Journal of Low Frequency Noise Vibration and Active Control, 30(4), 291-312.

8. Brüel \& Kjaer, 2002. Human Vibration, Brüel \& Kjaer Sound \& Vibration Measurement A/S, Nærum, Denmark.

9. European Union (EU), 2006. EU Guide to Good Practice on Hand Arm Vibration; Implementation of Directive 2002/44/EC, England.

10. Çalışma ve Sosyal Güvenlik Bakanlığı (ÇSGB), 2013. Çalışanların Titreşimle İlgili Risklerden Korunmalarına Dair Yönetmelik, Ankara.

11. European Union (EU), 2006. Non-Binding Guide to Good Practice With a View to Implementation of Directive 2002/44/EC on the Minimum Health and Safety Requirements Regarding the Exposure of Workers to the Risks Arising From Physical Agents (Vibrations), Directorate-General for Employment, Social Affairs and Inclusion, European Commission, ISBN: 978-92-7907533-9, 61 .

12. İşsever, H., 1999. Vibrasyon ve İnsan Sağlığ1 Üzerindeki Etkileri, İş Sağlığı ve Güvenliği Konferans1, 85-98.

13. Xu, X., Yuan, Z., Gong, M., He, L., Wang, R., Wang, J., Yang, Q., Wang, S., 2017. Occupational Hazards Survey Among Coal Workers Using Hand-Held Vibrating Tools in a 
Northern China Coal Mine, International Journal of Industrial Ergonomics, 62, 21-26.

14. Wang, L., Zhang, C., Zhang, Q., Zhang, K., Zeng, X., 2005. The Study on Hand-Arm Vibration Syndrome in China, Institute for Occupational Health and Environmental Medicine, 43, 480- 483.

15. TS EN 1032+A1, 2011. Türk Standartlar1, Mekanik Titreşim-Titreşim Emisyon Değerinin Belirlenmesi Amacıyla Hareketli Makinaların Deneye Tabi Tutulması, TSE, Ankara.

16. Arıtan, A.E., Şensöğüt, C., Ören, Ö., Tümer, M., 2016. Kırmataş Sektöründe Titreşim Problemine Genel Bakış, 8. Uluslararası Kırmataş Sempozyumu, 439-444, Kütahya. 
